\title{
Age Differences in Exposure and Reactions to Interpersonal Tensions: A Daily Diary Study
}

\author{
Kira S. Birditt \\ University of Michigan
}

\author{
Karen L. Fingerman \\ Purdue University
}

\author{
David M. Almeida \\ Pennsylvania State University University Park Campus
}

\begin{abstract}
This study examines age differences in exposure and reactivity to interpersonal tensions. The data are from the National Study of Daily Experiences in which participants ages 25 to $74(N=666)$ completed phone interviews wherein they described interpersonal tensions and rated the stressfulness of the tensions each evening for 8 days. Coders rated descriptions for types of behavioral reactions. Multilevel models revealed older adults reported fewer interpersonal tensions, were more likely to report tensions with spouses, were less likely to report tensions with children, experienced less stress, and were less likely to argue and more likely to do nothing in response to tensions than were younger adults. Age differences in emotional and behavioral reactions did not appear to be due to variations in exposure to tensions. The discussion centers on why older people may be better able to regulate their reactions to problems than younger people.
\end{abstract}

Keywords: interpersonal problems, aging, conflict strategies, daily diary, stress

People's daily lives are characterized by interactions with family members (e.g., spouses, children), acquaintances (e.g., neighbors, coworkers), and friends. Although these social exchanges are often positive, they may also be negative. Of all the daily problems encountered, interpersonal problems are the most detrimental sources of stress (Bolger, DeLongis, Kessler, \& Schilling, 1989; Clark \& Watson, 1988; Repetti, 1993). Indeed, interpersonal tensions are better predictors of psychological well-being than other types of everyday events such as work overloads (Bolger et al., 1989).

The experience of interpersonal tensions may vary from early adulthood to old age. The life span literature postulates that as people grow older, they have fewer problems in their relationships, experience less distress, and become less aggressive and more conciliatory because they are exposed to different social contexts and/or are better able regulate reactions to problems (BlanchardFields \& Cooper, 2004; Carstensen, Isaacowitz, \& Charles, 1999; Labouvie-Vief, Hakim-Larson, \& Hobart, 1987; Lazarus, 1996). However, many of these findings are based on salient interpersonal

Kira S. Birditt, Institute for Social Research, University of Michigan; Karen L. Fingerman, Department of Child Development and Family Studies, Purdue University; David M. Almeida, Department of Human Development and Family Studies, Pennsylvania State University University Park Campus.

Data are from the National Study of Daily Experiences, which was conducted as part of the National Survey of Midlife Development sponsored by the John L. and Catherine T. MacArthur Foundation Research Network on Successful Midlife Development.

Correspondence concerning this article should be addressed to Kira S. Birditt, Institute for Social Research, University of Michigan, 426 Thompson Street, Ann Arbor, MI 48104-2321. E-mail: kirasb@isr.umich.edu problems within certain relationships (e.g., spouse, child). For example, researchers have observed participants engage in conflicts with spouses or children in laboratories, examined responses to vignettes regarding stressful interpersonal events such as infidelity or older sick parents, and assessed recollections of upsetting interactions (Birditt \& Fingerman, 2005; Blanchard-Fields, Jahnke, \& Camp, 1995; Carstensen, Gottman, \& Levenson, 1995; Fingerman, 1998). It is unclear whether the observed age differences exist in response to less salient interpersonal tensions that occur with the variety of social partners encountered on a daily basis.

The purpose of this study was to examine whether older and younger adults differ in exposure and reactivity to interpersonal problems in day-to-day life. We define exposure as the number of interpersonal problems individuals experienced and the type of social partners (e.g., spouse, child, acquaintance) with whom they experienced problems. Reactivity, on the other hand, involves how a person responds emotionally and behaviorally to that tension. In order to examine these issues, we used daily reports of tensions, which allowed us to assess the variety of social partners who irritate adults of different ages and how they respond to those irritations. In addition, by examining daily reports, we were able to assess whether intraindividual differences in exposure accounted for variations in reactivity.

\section{Age and Exposure to Interpersonal Tensions}

The number of interpersonal tensions people are exposed to may vary across the life span. When asked to give aggregate reports regarding negativity in their relationships, older people, in comparison with younger people, reported that their relationships are less irritating, less demanding, and involve less criticism 
(Akiyama, Antonucci, Takahashi, \& Langfahl, 2003; Fingerman \& Birditt, 2003; Okun \& Keith, 1998; Rook, 1984; Walen \& Lachman, 2000). Therefore, we predicted that older adults would report experiencing fewer tensions than younger people on a daily basis.

The types of social partners who generate irritation may also differ from early adulthood to old age. Age-related changes in marital, parental, and employment status (Bureau of the Census, 2004; Bureau of Labor Statistics, 2005; Crnic \& Acevado, 1995; Moen, 2001; Pearlin \& Turner, 1987) may lead to variations in the types of social partners with whom people report problems (e.g., spouses, children, coworkers, other family). In addition, Carstensen and her colleagues (1999) have suggested that as people age, they purposefully reduce contact with acquaintances as a means of decreasing the likelihood of negative encounters. Researchers have yet to examine whether there are variations in the types of social partners with whom adults of different ages report tensions in their day-to-day lives.

We examined age differences in the types of social partners who generate tensions, including spouse, child, other family, and nonfamily relationships (e.g., coworkers, friends). Previous researchers have examined more detailed categories, such as mother, father, best friend, child, and spouse (Lansford, Antonucci, Akiyama, \& Takahashi, 2005) as well as less detailed categories (e.g., spouse, relative, friend; Schuster, Kessler, \& Aseltine, 1990; Walen \& Lachman, 2000). We chose to examine spouse, child, other family members, and nonfamily relationships (e.g., acquaintance, friend, coworker) because they link with different roles (Bolger et al., 1989; Fingerman, Hay, \& Birditt, 2004) and because some specific relationship categories (e.g., parent, sibling, friend) had low frequencies of tensions. We predicted that older people would be less likely to report tensions with nonfamily members (e.g., acquaintances, friends) than would younger people.

\section{Age and Reactivity to Interpersonal Tensions}

Not only are there possible age variations in exposure to interpersonal tensions, there also may be age differences in reactions to these stressors. Indeed, older people may have less intense emotional reactions to interpersonal tensions than younger people. Older adults appraise daily events as less stressful than do younger adults (Aldwin, 1991; Almeida \& Horn, 2004) and they are less likely to report negative emotions in general (Carstensen, Pasupathi, Mayr, \& Nesselroade, 2000; Gross et al., 1997). In a recent study, we examined age differences in the emotions reported in response to recollections of salient interpersonal tensions and found that older people were less likely to report anger in response to problems than were younger people (Birditt \& Fingerman, 2003). We hypothesized that older people would report less stress in response to interpersonal problems than would younger people.

Behavioral reactions to interpersonal tensions may also vary with age. However, findings are obscured by variations in the definitions of behavioral reactions. Everyday coping theorists have usually defined coping along two major dimensions, problem versus emotion focused (Folkman \& Lazarus, 1980; Folkman, Lazarus, Pimley, \& Novacek, 1987), which are also referred to as active versus passive strategies, respectively. Active strategies include directly attempting to solve the problem, such as cognitive analysis, confrontive coping, and planful problem solving. Passive strategies involve avoiding the problem and focusing on emotional reactions, such as expressing emotions, suppressing emotions, asking for help from others, passive dependence (withdrawing, doing nothing), avoidant denial (denial, selective attention, emotional suppression), religion, and alcohol-drug use (BlanchardFields et al., 1995; Carver, Scheier, \& Weintraub, 1989; Cornelius \& Caspi, 1987; Folkman et al., 1987).

In contrast, the interpersonal conflict literature has often conceptualized behavioral reactions as constructive, destructive, and avoidant (Acitelli, Douvan, \& Veroff, 1993; Canary, Cunningham, \& Cody, 1988; Coyne, Thompson, \& Palmer, 2002; Fingerman, 1998; Noller \& Feeney, 1998). Constructive behaviors are active and beneficial for the relationship, such as compromising, calm discussion, and listening. Destructive behaviors are active but may be harmful for the relationship, such as yelling, insulting, threatening, criticizing, and physical violence. Avoidance is passive and consists of changing the topic of conversation, ignoring the social partner, withdrawal, sulking, leaving the room, and denying there is a problem.

In the present study, we used a definition of behavioral reactions that combined the active-passive as well as the constructivedestructive dimensions from the personal relationships literature (Davis, Capobianco, \& Kraus, 2004; Rusbult, Bissonnette, Arriaga, \& Cox, 1998; Sillars, 1986). Active destructive behaviors include overt behaviors that are potentially harmful to the relationship, such as yelling, hitting, and arguing. Passive destructive strategies are avoidant behaviors that are potentially harmful to the relationship, such as pretending the social partner does not exist, sulking, or avoiding interactions. Active constructive behaviors are aimed to directly solve the problem and are potentially beneficial for the relationship, such as discussing the issue, compromising, or complying. Passive constructive strategies include avoidant behaviors that may be beneficial for the relationship, such as doing nothing or engaging in affirming behaviors not related to the problem.

As means of validating the constructive-destructive dimension, Rusbult, Johnson, and Morrow (1986) found that destructive behaviors lead to poor relationship outcomes whereas constructive behaviors lead to better relationship outcomes. However, because the present study does not include assessments of relationship functioning, we can only assume that these behaviors are constructive or destructive for relationships. This issue is discussed in more detail in the Discussion.

Using various conceptions of behavior, researchers have generally concluded that there are age differences in reactions to interpersonal tensions. Everyday problem-solving researchers concluded that older adults are less likely to use problem-focused strategies (active) and more likely to use emotion-focused strategies (passive; Diehl, Coyle, \& Labouvie-Vief, 1996; Folkman et al., 1987). However, age differences vary by emotional salience and domain of the stress. Older adults reported using more passive strategies than younger adults in response to emotionally salient vignettes and interpersonal situations (Blanchard-Fields, Chen, \& Norris, 1997; Blanchard-Fields et al., 1995; Watson \& BlanchardFields, 1998).

Interpersonal conflict researchers have found more inconsistent results. Older people are more likely to use constructive strategies such as affection and discussion and less likely to use destructive strategies such as belligerence in response to marital conflict as 
compared with younger people (Carstensen et al., 1995; Sillars \& Zietlow, 1993). In contrast, Fingerman (1998) observed mothers and daughters discussing interpersonal tensions and found that mothers (mean age $=76$ ) were more likely to avoid open discussion about the problem than daughters (mean age $=44$ ). These findings may be inconsistent because they were derived from different relationships (i.e., spouses vs. children; Carstensen et al., 1995; Fingerman, 1998).

Thus, in a recent study, we assessed retrospective reports of salient interpersonal conflicts across a variety of relationships and found that older people were more likely to report passive constructive (e.g., doing nothing) and less likely to report active destructive (e.g., yelling) strategies than younger people (Birditt \& Fingerman, 2005). However, the findings are based on accounts of particularly salient conflicts. It is possible that older adults are only more likely to use passive strategies in response to salient conflicts (Blanchard-Fields et al., 1995).

In the present study, we attempted to examine how people behave in response to everyday interpersonal tensions ranging in salience. We predicted that older adults would report more passive constructive strategies and less active destructive strategies than would younger adults. In addition, we examined whether age differences in emotional and behavioral reactivity could be accounted for by differential exposure to interpersonal tensions. According to life span theories, older people may experience stress differently than do younger people because they are exposed to dissimilar stressors (Carstensen et al., 1999; Lazarus, 1996). We predicted that age differences in emotional and behavioral reactivity would be partially accounted for by the type of social partner and the number of tensions to which people were exposed.

Although not a main focus, we also considered gender. Gender theorists suggest that women are more likely to ruminate about problems and feel more burdened by the problems of others than are men (Antonucci, 2001; Nolen-Hoeksema, Larson, \& Grayson, 1999). Indeed, researchers have found that women tend to report a greater number of interpersonal problems and report more distress in response to problems than do men (Almeida \& Kessler, 1998; Birditt \& Fingerman, 2003). In addition, women tend to use demand strategies, whereas men tend to withdraw when they experience tensions in marital or romantic relationships (Christensen \& Heavey, 1990; Markman, Silvern, Clements, \& KraftHanak, 1993). Thus, we predicted that women would report a greater number of interpersonal tensions, more stress, and more active strategies than would men.

\section{Method}

\section{Participants}

The present study involved 666 participants who described interpersonal tensions in the National Study of Daily Experiences (NSDE). Potential participants for the NSDE $(N=1,242)$ were randomly selected from people who completed the phone and mail surveys from the National Survey of Midlife Development (MIDUS), and 1,031 agreed to participate (Almeida, 2005; Almeida, Wethington, \& Kessler, 2002). Participants received $\$ 20$ for participation. Of those 1,031 participants, 2 were excluded from the study because of missing data regarding their age. NSDE participants completed a mean of 7 days of phone interviews, which summed to a total of 7,221 interviews (Almeida et al., 2002).

Participants completed 10- to 15-min phone interviews each evening for 8 consecutive days (Almeida, 2005; Almeida et al., 2002). On the 8th evening, they responded to a series of questions regarding the previous week. The data were collected during 40 separate 8 -week sessions across an entire year. The specific day of the week in which the sessions began varied across days of the week to control for biases due to confounding the number of days in the study and day of the week (e.g., Monday, Friday).

We examined the participants who described interpersonal tensions. Interpersonal tensions include either avoiding or engaging in arguments. A total of 666 people described at least one interpersonal tension; 411 participants described more than one interpersonal tension. Participants reported a total of 1,618 interpersonal tensions $(M=2.43$ tensions per participant, $S D=1.74$, range $=1$ to 14 tensions). Thus, $35.3 \%$ of the NSDE sample did not report an interpersonal tension. See Table 1 for a demographic breakdown of participants who described interpersonal problems.

\section{Age and Gender}

Consistent with prior studies (Almeida \& Horn, 2004; Walen \& Lachman, 2000), we divided age into three categories: younger adults (ages 25

Table 1

Percentages of the Participants Who Completed the National Study of Daily Experiences (NSDE) and Participants Who Provided Description of Interpersonal Tensions Fitting Each Background Characteristic

\begin{tabular}{|c|c|c|c|}
\hline Demographic variable & Breakdown & $\begin{array}{c}\text { NSDE } \\
(N=1,029)\end{array}$ & $\begin{array}{l}\text { Interpersonal tension } \\
\qquad(n=666)\end{array}$ \\
\hline \multirow[t]{3}{*}{ Age } & Young adults (25-39-year olds) & 32.5 & 35.3 \\
\hline & Middle-aged adults (40-59-year olds) & 45.7 & 47.0 \\
\hline & Older adults (60-74-year olds) & 21.8 & 17.7 \\
\hline \multirow[t]{2}{*}{ Gender } & Men & 44.9 & 42.9 \\
\hline & Women & 55.1 & 57.1 \\
\hline \multirow[t]{2}{*}{ Marital status } & Married & 65.4 & 66.5 \\
\hline & All others & 34.6 & 33.5 \\
\hline \multirow[t]{2}{*}{ Education } & 12 years or less & 37.7 & 35.6 \\
\hline & 13 years or more & 62.3 & 64.4 \\
\hline \multirow[t]{3}{*}{ Ethnicity } & Caucasian & 90.0 & 89.0 \\
\hline & African American & 5.9 & 5.1 \\
\hline & All other races & 4.1 & 5.9 \\
\hline \multirow[t]{2}{*}{ Employment } & Employed & 59.9 & 62.2 \\
\hline & All others & 40.1 & 37.8 \\
\hline
\end{tabular}


to 39), middle-aged adults (ages 40 to 59), and older adults (ages 60 to 74). Women were coded as 0 and men were coded as 1 .

\section{Education}

Participants reported the highest grade or year of college completed. Responses were grouped into 12 categories, which ranged from 1 (some grade school) to 12 (PhD or other professional degree).

\section{Health Status}

Participants rated their health on a scale from 1 (poor) to 5 (excellent; Idler \& Kasl, 1991, 1995).

\section{Descriptions of Interpersonal Tensions}

We examined descriptions of tensions from a series of seven stem questions used to obtain accounts of a variety of stressful experiences (Daily Inventory of Stressful Experiences; Almeida et al., 2002). Participants provided open-ended descriptions of the stressors that they experienced each day. As part of the initial NSDE data, research assistants tape-recorded, transcribed, and coded the descriptions. The codes included argument, avoid argument, other-neither, or nonevent (Almeida, 1998). Two independent raters coded approximately $20 \%$ (800) of the descriptions, and their kappa was .90 (Almeida et al., 2002). Five hundred eighty-eight of the interpersonal tensions were coded as arguments, which were defined as verbal exchanges, and 1,030 were coded as arguments that were avoided.

\section{Behavioral Reactions}

In the present study, we coded descriptions originally categorized as an argument or avoiding an argument in terms of the behavioral reactions participants reported in response to those tensions. Two undergraduate research assistants coded the descriptions with 12 mutually exclusive dichotomous codes $(0=$ does not include the behavior or $1=$ does include the behavior) that fit into four conflict strategy categories: active destructive, passive destructive, active constructive, and passive constructive.

As in our prior work (Birditt \& Fingerman, 2003; Birditt \& Fingerman, 2005), Kira S. Birditt and the assistants developed the codes with deductive and inductive techniques (King, 2004; Strauss, 1987). Using previous research, they began with a list of behaviors that fit into the four behavioral reaction categories (active destructive, passive destructive, active constructive, and passive constructive; Canary, Cupach, \& Messman, 1995; Putnam $\&$ Wilson, 1982; Rusbult et al., 1998; Straus, 1979). Then they met weekly to redefine and add codes. The final coding system included a total of 12 mutually exclusive codes; 9 codes derived from previous research and 3 data inductive codes (see Table 2).

Finally, two research assistants established interrater reliability on a total of 320 descriptions. To establish initial reliability before the coding occurred, the research assistants categorized 120 descriptions. In order to assure that the raters remained consistent, they overlapped on 40 descriptions a week. The coders discussed cases when disagreements arose and reached a consensus. The kappas for the categories that we examined ranged from .66 to .92 . Even though kappas greater than .70 are most desirable, kappas for dichotomous codes are often underestimates of interrater reliability (Bakeman, Quera, McArthur, \& Robinson, 1997). Table 2 lists the kappa coefficients for each code. Five codes were excluded because they were reported by fewer than $3 \%$ of the 666 participants $(n=$ 20 ), including physical aggression, compromising, saying something to make the person feel better, ignoring or avoiding the person, and leaving the situation. A total of $3 \%$ of the 1,618 transcripts were coded with behaviors later excluded.

In sum, we examined seven dichotomous behavioral reaction variables (discuss, comply, argue, verbally harm, do nothing, nonspecific active, and nonspecific passive). Discuss and comply are considered active constructive behaviors, argue and verbally harm are active destructive behaviors, and do nothing is a passive constructive behavior. The passive destructive behaviors were not included because too few people endorsed those responses (leave situation, ignore person). The nonspecific active and nonspecific passive data inductive codes captured responses from participants who indicated they engaged in an argument but who did not indicate how they argued (nonspecific active) and from participants who indicated that they avoided an argument but who did not indicate how they avoided the argument (nonspecific passive). It was not possible to determine whether these strategies were constructive or destructive. Of these seven strategy categories, across the descriptions of interpersonal tensions, each participant reported using an average of $1.81(S D=0.99)$ strategies.

Table 2

Description of Codes Used to Categorize Behavioral Reactions

\begin{tabular}{|c|c|c|c|}
\hline Code & $\kappa$ & $\begin{array}{l}\text { Proportion of tensions } \\
\qquad(n=1,618)\end{array}$ & $\begin{array}{l}\text { Proportion of participants } \\
\qquad(n=666)\end{array}$ \\
\hline \multicolumn{4}{|l|}{ Active constructive (AC) } \\
\hline 1. Participant discusses the problem, expresses opinion, makes suggestions. & .66 & .20 & .36 \\
\hline 2. Participant complies with target to solve the problem. & .66 & .02 & .04 \\
\hline \multicolumn{4}{|l|}{ Active destructive $(\mathrm{AD})$} \\
\hline 3. Participant and target argue or fight. & .66 & .10 & .21 \\
\hline 4. Participant uses verbally harmful behaviors: yelling, insults, cursing. & .92 & .04 & .08 \\
\hline \multicolumn{4}{|l|}{ Passive constructive (PC) } \\
\hline 5. Participant chooses not to say anything, ignore situation, let it pass. & .66 & .27 & .49 \\
\hline \multicolumn{4}{|l|}{ Nonspecific } \\
\hline 6. Situation coded as avoided argument but not specific (nonspecific passive). & .83 & .25 & .43 \\
\hline 7. Situation coded as argument but not specific (nonspecific active). & .69 & .10 & .19 \\
\hline \multicolumn{4}{|l|}{ Codes not examined because of low frequency of occurrence } \\
\hline 8. Participant and target reach compromise (AC). & .00 & .01 & .01 \\
\hline 9. Participant uses physically harmful behaviors against the target (AD). & .00 & .00 & .00 \\
\hline 10. Participant says or does something just to make target feel better (PC). & .50 & .01 & .02 \\
\hline 11. Participant physically leaves situation (PD). & .66 & .01 & .03 \\
\hline 12. Participant ignores the target or avoids interacting with the target (PD). & .57 & .00 & .01 \\
\hline
\end{tabular}

Note. $\mathrm{PD}=$ passive destructive. 


\section{Type of Social Partner}

The phone interview included a list of relationship types. On the basis of prior research and low frequencies for some social partners (e.g., parent, sibling), we categorized relationship types into spouse-partner, child, other family members (parent, sibling, grandchild, grandparent, other relative), and nonfamily relationships (friend, neighbor, coworker-fellow student, boss, teacher, employee, supervisee, stranger, group or organization member, client, customer, patient, service provider, and acquaintance; Schuster et al., 1990; Walen \& Lachman, 2000). We coded interpersonal tensions as four dichotomous variables ( 1 if the tension was with a social partner who fit into the specific category such as spouse-partner or 0 if the tension was not with a social partner who fit that relationship category).

\section{Emotional Reactivity}

Participants rated the stressfulness of the tensions on a scale that ranged from 1 (not at all stressful) to 4 (very stressful). Although the use of a single item is not ideal, the NSDE utilized this method in order to limit the demands on participants.

\section{Results}

\section{Overview of Analysis Strategy}

Because participants reported different numbers of interpersonal tensions across days, we used multilevel modeling to account for unequal numbers of lower level units (interpersonal tensions) nested within upper level units (study participant; Singer, 1998). The upper level units included the characteristics of the participants (age, gender, health, education), and the lower level units included the aspects of the daily tensions (type of social partner, number of tensions that day, emotional reactions, behavioral reactions). We used the PROC MIXED procedure in SAS to analyze the multilevel models (Littell, Milliken, Stroup, \& Wolfinger, 1996; Singer, 1998). PROC MIXED assesses linear and nonlinear models that include upper and lower level variables as predictors in the same equation.

Independent variables. The upper level independent variables included participants' age and gender. We entered age as dummy variables: younger adults and middle-aged adults with older adults as the comparison group.

Dependent variables. The dependent variables included number of tensions, type of social partner, emotional reactivity, and behavioral reactions. The number of tensions included a count of the number of interpersonal tensions experienced each day. Social partners consisted of dummy variables: spouse-partner, child, and other family with nonfamily relationships as the comparison group. Emotional reactivity referred to the ratings of the stressfulness of the tensions. Behavioral reactivity included dummy variables for types of behavioral reaction (argue, verbally harm, discuss, comply, do nothing, nonspecific active, and nonspecific passive).

Controls. Health and education were included as control variables in all analyses because they may be confounded with age and gender. Two $2 \times 3$ (Gender $\times$ Age) analyses of variance were conducted to examine whether education and health varied by age and gender. We found that education varied by age, $F(2,660)=$ 5.34, $p<.01$, and gender, $F(1,660)=8.54, p<.01$. Middle-aged adults indicated they had more education than the younger and older adults, and men indicated they had more education than women. In addition, health varied by age, $F(2,660)=6.48, p<$ .01 . Older adults rated their health as poorer than did younger and middle-aged adults.

\section{Age Differences in Exposure to Interpersonal Tensions}

The purpose of the following analyses was to examine whether there are age differences in the extent to which people are exposed to interpersonal problems in their day-to-day lives. Exposure to problems includes the number of problems experienced as well as the type of social partner with whom the problem occurred. First, we assessed whether the number of interpersonal tensions reported each day varied by age. Tables 3 and 4 include the descriptive statistics and the multilevel modeling results for the number of interpersonal tensions reported each day as well as emotional reactivity, which will be discussed later. We estimated one multilevel model. The upper level independent variables included age, gender, and the interaction between age and gender. We controlled for health and education.

\section{General Mathematical Model}

The general mathematical model was

$$
\begin{aligned}
N T_{i t}=a_{0}+a_{1}\left(\mathrm{Age}_{i}\right)+a_{2} & \left(\text { Gender }_{i}\right) \\
& +a_{3}\left(\text { Age } \times \text { Gender }_{\mathrm{i}}\right)+e_{\mathrm{i}}+d_{i t},
\end{aligned}
$$

Table 3

Means and Standard Deviations for Number of Interpersonal Tensions Reported Each Day and

\begin{tabular}{|c|c|c|c|c|c|c|}
\hline \multirow[b]{2}{*}{ Age and gender group } & \multicolumn{3}{|c|}{ Emotional reactivity } & \multicolumn{3}{|c|}{ No. of tensions } \\
\hline & $M$ & $S D$ & Range & $M$ & $S D$ & Range \\
\hline \multicolumn{7}{|l|}{ Young adults } \\
\hline Men & 2.68 & 0.96 & $1.00-4.00$ & 1.35 & 0.56 & $1.00-3.00$ \\
\hline Women & 2.92 & 0.86 & $1.00-4.00$ & 1.28 & 0.54 & $1.00-3.00$ \\
\hline \multicolumn{7}{|l|}{ Middle-aged adults } \\
\hline Men & 2.56 & 0.93 & $1.00-4.00$ & 1.29 & 0.51 & $1.00-3.00$ \\
\hline Women & 2.83 & 0.81 & $1.00-4.00$ & 1.33 & 0.60 & $1.00-4.00$ \\
\hline \multicolumn{7}{|l|}{ Older adults } \\
\hline Men & 2.28 & 0.98 & $1.00-4.00$ & 1.13 & 0.34 & $1.00-2.00$ \\
\hline Women & 2.57 & 0.96 & $1.00-4.00$ & 1.20 & 0.45 & $1.00-3.00$ \\
\hline Total sample & 2.71 & 0.91 & $1.00-4.00$ & 1.29 & 0.54 & $1.00-4.00$ \\
\hline
\end{tabular}
Emotional Reactivity by Age and Gender 
Table 4

Multilevel Models Examining the Number of Tensions and Emotional Reactivity as a Function of Age and Gender

\begin{tabular}{lcccc}
\hline \multicolumn{1}{c}{ Source } & Estimate & $S E$ & $d f$ & $t$ \\
\hline No. of tensions & & & & \\
$\quad$ Intercept & 1.03 & 0.09 & 867 & $12.01^{* *}$ \\
$\quad$ Young adult & 0.16 & 0.07 & 926 & $2.29^{*}$ \\
$\quad$ Middle age & 0.13 & 0.07 & 916 & 1.87 \\
Older & & & & \\
Gender & 0.06 & 0.08 & 906 & 0.81 \\
Age $\times$ Gender & $n s$ & $n s$ & $n s$ & $n s$ \\
Emotional reactivity & & & & \\
$\quad$ Intercept & 2.60 & 0.15 & 625 & $17.27^{* *}$ \\
$\quad$ Young adult & 0.46 & 0.13 & 685 & $3.62^{* *}$ \\
$\quad$ Middle age & 0.43 & 0.12 & 683 & $3.56^{* *}$ \\
Older & & & & \\
Gender & -0.36 & 0.14 & 666 & $2.67 * *$ \\
Age $\times$ Gender & $n s$ & $n s$ & $n s$ & $n s$ \\
\hline
\end{tabular}

Note. Analyses control for health and education. $N=1,560$ for emotional reactivity and $N=1,594$ for exposure because of missing data.

$* p<.05 . \quad * * p<.01$.

where $N T_{i t}=$ number of tensions experienced by participant $(i)$ on the day tension $(t)$ occurred; $a_{0}=$ intercept; Gender $_{i}=$ gender of participant $i$ Age $_{i}=$ age of participant $i ; a_{1}, a_{2}, a_{3}=$ slopes for age, gender, and Age $\times$ Gender interaction, respectively; $e_{i}=$ error between participants; and $d_{i t}=$ error associated with tensions (error within participants).

Among the participants who reported tensions, the number of tensions varied with age. Tukey's post hoc comparisons revealed that older adults reported fewer tensions each day than did younger or middle-aged adults (see Table 4). There were no gender differences in the number of tensions reported.

Then we examined age differences in the types of social partners with whom participants reported tensions. Overall, participants reported tensions with nonfamily relationships (e.g., coworkers, acquaintances) followed by spouses, children, and other family (see Table 5). We conducted four multilevel models: one for each type of social partner as the dependent variables (spouse, child, other family members, and nonfamily relationships). Because of the dichotomous dependent variables, we estimated nonlinear multilevel models with binomial error distributions. The independent variables included age, gender, and the interaction between age and gender. Controls included health and education.

We found that the likelihood of reporting tensions with spouse and child varied with age, $F(2,616)=6.37, p<.01 ; F(2,662)=$ $5.70, p<.01$, respectively. Tukey's post hoc comparisons revealed that older people were more likely to report tensions with spouses as compared with other relationships than were middleaged or younger people. In addition, older people were less likely to report tensions with children as compared with other relations than were middle-aged people. We also found a gender difference in reports of problems with children. Women were more likely to report problems with children than were men, $F(1,677)=10.12$, $p<.01$.

\section{Age Differences in Reactivity to Interpersonal Tensions}

The purpose of these analyses was to examine whether there are age differences in how people react to the interpersonal problems they experience in day-to-day life. Reactivity includes how people respond emotionally as well as behaviorally. First, we considered emotional reactivity (see Table 3 ). We estimated one multilevel model. The independent variables included age, gender, and the interaction between age and gender. We controlled for health and education. The dependent variable included ratings of the stressfulness of the tensions.

Emotional reactivity varied by age and gender (see Table 4). Tukey's post hoc comparisons revealed that older people reported that tensions were less stressful than did younger and middle-aged individuals. Women rated tensions as more stressful than did men.

We then considered whether reports of behavioral reactions varied by age and gender. People reported passive strategies most frequently (e.g., doing nothing; see Table 6). We estimated seven multilevel models: one for each type of conflict strategy as the dependent variables (argue, verbally harm, discuss, comply, do nothing, nonspecific active, nonspecific passive). Because we used dichotomous dependent variables, we estimated nonlinear multilevel models with binomial error distributions. The independent variables included age, gender, and the interaction between age and gender.

As predicted, the likelihood of reporting the use of arguing (active destructive) varied with age (see Table 7). Tukey's post hoc comparisons revealed that younger adults were more likely than older adults to report arguing. Reports of doing nothing (passive constructive) also varied with age; older people were more likely to report doing nothing than younger people. In addition, there was a significant interaction between age and gender when predicting nonspecific active strategies. Middle-aged and older men were more likely to describe nonspecific active strategies than younger adult men. There were no other age or gender differences in reported use of behavioral reactions.

Finally, we tested four mediation models that assessed whether age differences in emotional and behavioral reactions could be accounted for by exposure to stress (type of social partner, number of interpersonal tensions experienced). When mediation is tested with multilevel modeling, the predictor can be an upper or lower variable, but the mediator and the outcome are always lower level (Kenny, Kashy, \& Bolger, 1998). There are three steps involved in testing mediation. First, there must be an association between the predictor (age) and the outcome (emotional, behavioral reactivity). Second, there must be an association between the predictor (age)

Table 5

Proportion of Tensions Reported With Each Type of Social Partner by Age and Gender

\begin{tabular}{lcccc}
\hline & $\begin{array}{c}\text { Spouse- } \\
\text { partner }\end{array}$ & Child & $\begin{array}{c}\text { Other } \\
\text { family }\end{array}$ & Nonfamily \\
\hline Young adults & & & & \\
$\quad$ Men $(n=201)$ & .32 & .08 & .07 & .54 \\
$\quad$ Women $(n=347)$ & .31 & .23 & .12 & .35 \\
Middle-aged adults & & & & .06 \\
$\quad$ Men $(n=312)$ & .30 & .16 & .06 & .48 \\
$\quad$ Women $(n=431)$ & .25 & .23 & .06 & .45 \\
Older adults & & & & .07 \\
$\quad$ Men $(n=103)$ & .47 & .03 & .07 & .44 \\
$\quad$ Women $(n=137)$ & .42 & .10 & .15 & .33 \\
Total sample $(N=1,531)^{\mathrm{a}}$ & .31 & .17 & .08 & .43 \\
\hline
\end{tabular}

${ }^{\text {a }} N=1,531$ because of missing data on the social partner variable. 
Table 6

Proportion of Tensions Categorized Into Each Behavioral Reaction by Age and Gender

\begin{tabular}{lccccccc}
\hline Age and gender group & Discuss & Comply & Argue & $\begin{array}{c}\text { Verbally } \\
\text { harm }\end{array}$ & $\begin{array}{c}\text { Do } \\
\text { nothing }\end{array}$ & $\begin{array}{c}\text { Nonspecific } \\
\text { active }\end{array}$ & $\begin{array}{c}\text { Nonspecific } \\
\text { passive }\end{array}$ \\
\hline $\begin{array}{l}\text { Young adults } \\
\quad\end{array}$ & & & & & & & \\
$\quad$ Men $(n=219)$ & .21 & .03 & .12 & .04 & .25 & .06 & .27 \\
$\quad$ Women $(n=361)$ & .18 & .01 & .14 & .06 & .23 & .10 & .24 \\
Middle-aged adults & & & & & & & .26 \\
$\quad$ Men $(n=333)$ & .24 & .02 & .08 & .03 & .23 & .13 & .25 \\
$\quad$ Women $(n=447)$ & .18 & .01 & .11 & .03 & .30 & .08 & .22 \\
Older adults & & & & & & \\
$\quad$ Men $(n=109)$ & .19 & .04 & .05 & .02 & .32 & .13 & .25 \\
$\quad$ Women $(n=149)$ & .17 & .04 & .08 & .02 & .33 & .08 & .25 \\
Total $(N=1,618)$ & .20 & .02 & .10 & .04 & .27 & .10 & .25 \\
\hline
\end{tabular}

and the mediator (social partner, number of tensions). Third, the mediator and predictor are entered together as predictors of the outcome. Complete mediation is evident when the predictor no longer predicts the outcome once the mediator is added to the model (Kenny et al., 1998).

First, we examined whether exposure (number of tensions, social partner) accounted for age differences in emotional and behavioral reactivity. The number of tensions was not associated with emotional or behavioral reactivity. Then we assessed whether the type of social partner accounted for age and gender differences in emotional and behavioral reactivity. First, we conducted one multilevel analysis, with social partner, age, gender, and the interaction between age and gender as predictors and ratings of stress as the dependent variable. We found that emotional reactivity varied by relationship category, $F(3,1454)=2.90, p<.05$.

Table 7

Multilevel Models Examining Behavioral Reactions as a Function of Age and Gender

\begin{tabular}{lcccc}
\hline \multicolumn{1}{c}{ Source } & Estimate & $S E$ & $d f$ & $t$ \\
\hline Argue & & & & \\
$\quad$ Intercept & -2.49 & 0.57 & 553 & $-4.38^{* *}$ \\
$\quad$ Young adult & 1.13 & 0.51 & 635 & $2.20^{*}$ \\
$\quad$ Middle age & 0.62 & 0.51 & 645 & 1.22 \\
Older & & & & \\
Gender & -0.58 & 0.56 & 639 & -1.04 \\
$\quad$ Age $\times$ Gender & $n s$ & $n s$ & $n s$ & $n s$ \\
Nothing & & & & \\
Intercept & -0.77 & 0.31 & 475 & $-2.50^{*}$ \\
Young adult & -0.38 & 0.27 & 569 & -1.44 \\
Middle age & -0.49 & 0.25 & 593 & $-1.96^{*}$ \\
Older & & & & \\
Gender & -0.01 & 0.28 & 591 & -0.03 \\
Age $\times$ Gender & $n s$ & $n s$ & $n s$ & $n s$ \\
Nonspecific active & & & & \\
$\quad$ Intercept & -2.41 & 0.48 & 491 & $-4.99^{* *}$ \\
$\quad$ Young adult & -0.92 & 0.44 & 561 & $-2.09 *$ \\
Middle age & -0.07 & 0.35 & 591 & -0.21 \\
Older & & & & \\
Gender & 0.49 & 0.44 & 570 & 1.11 \\
Young Adult $\times$ Woman & 1.20 & 0.58 & 532 & $2.08^{*}$ \\
$\quad$ Middle Aged $\times$ Woman & 0.01 & 0.51 & 536 & 0.02 \\
\hline
\end{tabular}

Note. $\quad N=1,594$ because of missing values on the health and education variables.

$* p<.05 . \quad * * p<.01$.
Tukey's comparisons indicated that people interpreted tensions with spouses as less stressful than tensions with children. Age was still highly significant and thus the association between age and emotional reactivity did not appear to be mediated by type of social partner.

Next we examined whether the type of social partner accounted for age and gender differences in behavioral reactions. We estimated two multilevel models, one for each behavioral reaction (do nothing, arguing). The likelihood of arguing varied with type of social partner, $F(3,1169)=11.83, p<.01$. Tukey's post hoc comparisons revealed that people were less likely to argue with acquaintances and other family members than with spouses and children. Type of social partner, however, did not mediate the relationship between age, gender, and behavioral reactions because the association between age and arguing increased when social partner was added to the model. This increase is most likely due to a statistical artifact or suppressor effect in which the association between the predictor and the outcome increase after adding a third variable because the predictor and third variable are correlated (MacKinnon, Krull, \& Lockwood, 2000).

We conducted some additional analyses to examine whether conflict strategies mediated or could account for age differences in emotional reactivity (stress) and exposure (number of tensions and type of social partner). We found no evidence for mediation; the age effect was still significant in all models. Therefore, in the interest of space, these analyses are not presented.

We also assessed whether age differences in exposure and reactivity may be due to habituation or repeated experiences with conflict in particular relationships. We conducted eight multilevel models examining age differences in the number of tensions and stress for each relationship type (spouse, child, other family members, and nonfamily relationships). The dependent variables included the number of tensions and emotional reactivity; age and gender were the independent variables. We controlled for health and education. The number of tensions and emotional reactivity varied by age for only the spousal relationship, $F(2,261)=4.19$, $p<.05 ; F(2,257)=15.70, p<.01$, respectively. Thus, it is possible that older adults reported fewer tensions and less emotional reactivity than younger adults because they have habituated to problems in the spousal relationship.

In addition, because of low cell sizes, we used chi-square tests, rather than conducting multilevel models, to examine whether the likelihood of reporting arguing or doing nothing varied by age 
group for each type of relationship. We found a significant age difference in the likelihood of reporting arguing in the nonfamily relationship, $\chi^{2}(2, N=661)=13.99, p<.01$. It appears that older people were less likely to report arguing in the nonfamily relationship as compared with younger age groups. All other chi-square tests were nonsignificant. Thus, overall, age was not associated with conflict strategies within specific relationships, which does not support the habituation hypothesis.

\section{Discussion}

This study examined the interpersonal problems that adults of different ages experience with a variety of social partners in day-to-day life. The findings suggest that the extent to which people were exposed to interpersonal problems as well as their reactions to those problems varied from younger adulthood to old age. Older people reported fewer interpersonal tensions than younger people. However, when older adults did report tensions, the tensions were more likely to occur with spouses, less likely to occur with children, were perceived as less stressful, and older adults were more likely to do nothing rather than argue as compared with younger adults. Exposure to problems did not account for age differences in reactions to problems. Overall, these findings suggest that people may become better able to regulate their responses to problems as they age.

\section{Age Differences in Exposure}

As we predicted, older people reported fewer interpersonal tensions than younger people. This finding is in line with the literature indicating that older adults report their relationships are less problematic than do younger adults (Akiyama et al., 2003; Fingerman \& Birditt, 2003) and life span theories, which suggest that older adults are exposed to different stressors than younger adults (Lazarus, 1996). Thus, it appears that overall relationship sentiments as well as daily interactions are less negative among older people.

Unlike our predictions, we found no age difference in the likelihood of reporting tensions with nonfamily relationships (e.g., friends, acquaintances). These results may be due to the lack of participants older than 75. Carstensen and her colleagues (1999) have suggested that people are most likely to prefer intimate social partners and reduce contact with acquaintances when they are close to death. However, we did find that older individuals reported fewer irritations with children and more problems with spouses as compared with other relationships than did younger individuals. This may have occurred because older adults' children have often moved out and they have more contact with spouses because of retirement.

Not surprisingly, women were more likely to report tensions with children than were men. This is most likely due to their greater child-care responsibilities and investment in their children (Troll, 1987). Indeed, findings from the current sample showed that on days when men spent more time with their children, they reported interpersonal tensions with them (Almeida, McDonald, \& Wethington, 2001).

\section{Age Differences in Reactivity}

According to life span theories, as people grow older, they become better able to regulate their responses to problems because they are more cognitively mature and more concerned with maintaining emotionally close interpersonal relationships (BlanchardFields \& Cooper, 2004; Carstensen et al., 1999; Labouvie-Vief et al., 1987). On the basis of these theories and previous research findings, we predicted that older people would report less emotional reactivity and would be less likely to report active destructive strategies (e.g., argue, verbally harm) and more likely to report passive constructive strategies (do nothing) than younger people.

As per our hypothesis, older adults reported that interpersonal tensions were less stressful than younger and middle-aged adults. This finding is in keeping with research indicating that older adults report less negative emotion in general and less anger in response to interpersonal problems than do younger adults (Birditt \& Fingerman, 2003; Carstensen et al., 2000; Gross et al., 1997). Women reported greater stress in response to problems than men. Women may experience more stress because they are more likely to ruminate and are more burdened by the problems of others than men (Antonucci, 2001; Nolen-Hoeksema et al., 1999).

Consistent with our expectation, we also found that older people were less likely to report arguing (active destructive) than younger people (Birditt \& Fingerman, 2005; Carstensen et al., 1995). Unfortunately, we were not able to examine passive destructive responses because of the low frequency of responses. It is possible that people use tactics such as leaving the situation or ignoring others less frequently than other strategies such as doing nothing. However, it is also possible that this response was not captured because of shortness of the descriptions. Further research should collect more details regarding avoidant responses.

As expected, older adults were more likely to describe passive constructive behavioral reactions (e.g., doing nothing) than younger adults (Fingerman, 1998; Watson \& Blanchard-Fields, 1998). This finding is consistent with Blanchard-Fields and her colleagues' (1995) proposition that older people are more likely to regulate their emotional responses by using passive strategies especially in salient social-emotional situations (Blanchard-Fields et al., 1995). It appears that age differences also exist in response to less salient conflicts that occur on a daily basis.

There were no age group differences in active constructive strategies such as discussion. Similarly, we found no age differences in the use of active constructive strategies reported in response to retrospective accounts of interpersonal problems (Birditt $\&$ Fingerman, 2005). Active constructive strategies involve revealing that there is a problem, which some older people may view as potentially stressful.

Reports of nonspecific active strategies varied by age only among men. Middle-aged and older men were more likely than younger men to indicate that they engaged in an argument and not describe it in detail. This finding is similar to our previous research indicating that middle-aged men were more likely to describe nonspecific negative emotions in response to interpersonal problems, whereas women reported specific emotions (Birditt \& Fingerman, 2003). Middle-aged and older men may be less able or willing to describe specific details regarding interpersonal problems because of cohort differences in beliefs regarding appropriate behaviors for men.

The failure to find overall gender differences in reported use of strategies across relationships was consistent with previous research. Although researchers have found gender differences in specific relationships (Christensen \& Heavey, 1990; Eagly \& 
Steffen, 1986), it does not appear that there are overall gender differences in conflict strategies across types of social partners (Birditt \& Fingerman, 2005). It is also possible that gender differences in conflict strategies vary depending on the emotional closeness of the relationship (Canary \& Emmers-Sommer, 1997). However, we did not assess the closeness of the relationships in which people reported tensions.

In addition, although the number of interpersonal tensions experienced each day varied by age, this variation in exposure did not account for emotional or behavioral reactions. This was somewhat surprising because researchers have found that the greater number of problems people are exposed to, the more likely they are to use destructive strategies such as physical aggression (Straus \& Gelles, 1990). It is possible that daily irritations examined in this study are more minor and common and thus did not accumulate and lead to differences in emotional and behavioral strategies.

Further, although the types of social partners with whom participants experienced problems varied by age, those variations did not account for age differences in emotional or behavioral reactivity. However, emotional and behavioral reactions did vary with the social partner. Tensions with children were rated as more stressful than tensions with spouses. Conflicts with spouse-partner and children were more likely to involve arguing than conflict with nonfamily relationships and other family members. People may be reluctant to argue in the context of nonfamily relations in particular because these interactions often occur in the public eye and may lead to criticism (Fingerman, 2004).

\section{Study Limitations}

There are limitations in the present study that should be addressed in future research regarding the daily experience of interpersonal problems. The sample was predominantly Caucasian. Researchers have found ethnic differences in social relationships. For example, Ajrouch, Antonucci, and Janevic (2001) discovered that African Americans have smaller social networks with more family members than Caucasians. It is possible that the manner in which people deal with the problems in their relationships varies depending on ethnicity because of variation in the number and types of people with whom they interact.

Further, age differences may reflect cohort differences. Indeed, older cohorts may consider it less acceptable than younger cohorts to use active destructive strategies. For example, younger adults have been exposed to more aggression and violence at an early age than older adults because of the increase of graphic violence in the media.

In addition, there were limitations in the way that the social partner variable was assessed. This study did not assess the quality of the relationships in which the conflict occurred. Rusbult and her colleagues (1998) have suggested that people respond more destructively in relationships they perceive as less close.

Finally, there is a lack of information regarding whether constructive and destructive strategies are differentially associated with relationship functioning. The implications of conflict strategies may vary depending on the interpersonal context. Doing nothing may be destructive if it is in response to a spouse's attempts to discuss a relationship problem. However, doing nothing may be beneficial if it is in response to a hurtful comment from a superior at work. Future research should obtain more detailed accounts of conflict strategies and examine whether they are associated with relationship functioning and well-being in different contexts.

In conclusion, it appears that men and women may become better able to deal with problems in their relationships as they age. However, further research needs to examine these processes longitudinally in order to explain those age differences. In addition, the vast majority of interpersonal tensions were responded to with passive constructive strategies and they occurred with nonfamily (e.g., acquaintances, coworkers) relationships. There is a dearth of research regarding acquaintances in particular and the use of avoidance in the social relationship literature. This research indicates more attention should be given to relations among acquaintances, the ways in which people avoid conflict, and whether those strategies are beneficial or harmful for personal well-being and relationship functioning.

\section{References}

Acitelli, L. K., Douvan, E., \& Veroff, J. (1993). Perceptions of conflict and similarity in the first year of marriage: How important are similarity and understanding? Journal of Social and Personal Relationships, 10, 5-19.

Ajrouch, K. J., Antonucci, T. C., \& Janevic, M. R. (2001). Social networks among Blacks and Whites: The interaction between race and age. Journals of Gerontology, Series B: Psychological Sciences and Social Sciences, 56, S112-S118.

Akiyama, H., Antonucci, T. C., Takahashi, K., \& Langfahl, E. S. (2003). Negative interactions in close relationships across the life span. Journals of Gerontology, Series B: Psychological Sciences and Social Sciences, 58, P70-P79.

Aldwin, C. M. (1991). Does age affect the stress and coping process? Implications of age differences in perceived control. Journal of Gerontology, 46, 174-180.

Almeida, D. M. (1998). Daily inventory of stressful events: Interview and coding manual. Unpublished manuscript, University of Arizona.

Almeida, D. M. (2005). Resilience and vulnerability to daily stressors assessed via diary methods. Current Directions in Psychological Science, 14, 64-68.

Almeida, D. M., \& Horn, M. C. (2004). Is daily life more stressful during middle adulthood? In O. G. Brim, C. D. Ryff, \& R. C. Kessler (Eds.), How healthy are we? A national study of well-being at midlife (pp. 425-451). Chicago: University of Chicago Press.

Almeida, D. M., \& Kessler, R. C. (1998). Everyday stressors and gender differences in daily stress. Journal of Personality and Social Psychology, 75, 670-680.

Almeida, D. M., McDonald, D., \& Wethington, E. (2001). Daily variation in father engagement and negative mood: Implications for nurturing and conflictual interactions. Journal of Marriage and the Family, 63, 417429.

Almeida, D. M., Wethington, E., \& Kessler, R. C. (2002). The Daily Inventory of Stressful Experiences (DISE): An interview-based approach for measuring daily stressors. Assessment, 9, 41-55.

Antonucci, T. C. (2001). Social relations. In J. E. Birren \& K. W. Schaie (Eds.), Handbook of the psychology of aging (pp. 53-77). San Diego, CA: Academic Press.

Bakeman, R., Quera, V., McArthur, D., \& Robinson, B. (1997). Detecting sequential patterns and determining their reliability with fallible observers. Psychological Methods, 2, 357-370.

Birditt, K. S., \& Fingerman, K. S. (2003). Age and gender differences in adults' descriptions of emotional reactions to interpersonal problems. Journals of Gerontology, Series B: Psychological Sciences and Social Sciences, 58, P237-P245.

Birditt, K. S., \& Fingerman, K. L. (2005). Do we get better at picking our 
battles? Age differences in descriptions of behavioral reactions to interpersonal tensions. Journals of Gerontology, Psychological Sciences and Social Sciences, 60(B), P121-128.

Blanchard-Fields, F., Chen, Y., \& Norris, L. (1997). Everyday problem solving across the adult life span: Influence of domain specificity and cognitive appraisal. Psychology and Aging, 12, 684-693.

Blanchard-Fields, F., \& Cooper, C. (2004). Social cognition and social relationships. In F. R. Lang \& K. L. Fingerman (Eds.), Growing together: Personal relationships across the lifespan (pp. 268-289). Cambridge, England: Cambridge University Press.

Blanchard-Fields, F., Jahnke, H. C., \& Camp, C. (1995). Age differences in problem-solving style: The role of emotional salience. Psychology and Aging, 10, 173-180.

Bolger, N., DeLongis, A., Kessler, R. C., \& Schilling, E. A. (1989). Effects of daily stress on negative mood. Journal of Personality and Social Psychology, 57, 808-818.

Bureau of the Census. (2004). America's families and living arrangements: 2003. Retrieved February 22, 2005, from http://www.census.gov/prod/ 2004pubs/p20-553.pdf

Bureau of Labor Statistics. (2005). The employment situation: January 2005. Retrieved February 22, 2005, from http://www.bls.gov/news. release/pdf/empsit.pdf

Canary, D. J., Cunningham, E. M., \& Cody, M. J. (1988). Goal types, gender, and locus of control in managing interpersonal conflict. Communication Research, 15, 426-446.

Canary, D. J., Cupach, W. R., \& Messman, S. J. (1995). Relationship conflict: Conflict in parent-child, friendship, and romantic relationships. Thousand Oaks, CA: Sage.

Canary, D. J., \& Emmers-Sommer, T. M. (1997). Sex and gender differences in personal relationships. New York: Guilford Press.

Carstensen, L. L., Gottman, J. M., \& Levenson, R. W. (1995). Emotional behavior in long-term marriage. Psychology and Aging, 10, 140-149.

Carstensen, L. L., Isaacowitz, D. M., \& Charles, S. T. (1999). Taking time seriously: A theory of socioemotional selectivity. American Psychologist, 54, 165-181.

Carstensen, L. L., Pasupathi, M., Mayr, U., \& Nesselroade, J. R. (2000). Emotional experience in everyday life across the adult lifespan. Journal of Personality and Social Psychology, 79, 1-12.

Carver, C. S., Scheier, M. F., \& Weintraub, J. K. (1989). Assessing coping strategies: A theoretically based approach. Journal of Personality and Social Psychology, 56, 267-283.

Christensen, A., \& Heavey, C. L. (1990). Gender and social structure in the demand/withdraw pattern of marital conflict. Journal of Personality and Social Psychology, 59, 73-81.

Clark, L. A., \& Watson, D. (1988). Mood and the mundane: Relations between daily life events and self-reported mood. Journal of Personality and Social Psychology, 54, 296-308.

Cornelius, S., \& Caspi, A. (1987). Everyday problem solving in adulthood and old age. Psychology and Aging, 2, 144-153.

Coyne, J. C., Thompson, R., \& Palmer, S. C. (2002). Marital quality, coping with conflict, marital complaints, and affection in couples with a depressed wife. Journal of Family Psychology, 16, 26-37.

Crnic, K., \& Acevedo, M. (1995). Everyday stresses and parenting. In M. H. Bornstein (Ed.), Handbook of parenting (Vol. 4, pp. 277-297). Hillsdale, NJ: Erlbaum.

Davis, M. H., Capobianco, S., \& Kraus, L. A. (2004). Measuring conflictrelated behaviors: Reliability and validity evidence regarding the conflict dynamics profile. Educational and Psychological Measurement, 64, 707-731.

Diehl, M., Coyle, N., \& Labouvie-Vief, G. (1996). Age and sex differences in strategies of coping and defense across the life span. Psychology and Aging, 11, 127-139.

Eagly, A. H., \& Steffen, V. J. (1986). Gender and aggressive behavior: A meta-analytic review of the social psychological literature. Psychological Bulletin, 100, 309-330.

Fingerman, K. L. (1998). Tight lips: Aging mothers' and their adult daughters' responses to interpersonal tensions in their relationship. Personal Relationships, 5, 121-138.

Fingerman, K. L. (2004). The consequential stranger: Peripheral relationships across the lifespan. In F. R. Lang \& K. L. Fingerman (Eds.), Growing together: Personal relationships across the lifespan (pp. 183209). Cambridge, England: Cambridge University Press.

Fingerman, K. L., \& Birditt, K. S. (2003). Does variation in close and problematic family ties reflect the pool of living relatives? Journals of Gerontology, Series B: Psychological Sciences and Social Sciences, 58, P80-P87.

Fingerman, K. L., Hay, E. L., \& Birditt, K. S. (2004). The best of ties, the worst of ties: Close, problematic, and ambivalent social relationships. Journal of Marriage and the Family, 66, 792-808.

Folkman, S., \& Lazarus, R. S. (1980). An analysis of coping in a middleaged community sample. Journal of Health and Social Behavior, 21, 219-239.

Folkman, S., Lazarus, R. S., Pimley, S., \& Novacek, J. (1987). Age differences in stress and coping processes. Psychology and Aging, 2, $171-184$.

Gross, J., Carstensen, L. L., Pasupathi, M., Tsai, J., Goetestsam Skorpen, C., \& Hsu, A. Y. C. (1997). Emotion and aging: Experience, expression, and control. Psychology and Aging, 12, 590-599.

Idler, E. L., \& Kasl, S. (1991). Health perceptions and survival: Do global evaluations of health status really predict mortality? Journal of Gerontology, 46, 55-65.

Idler, E. L., \& Kasl, S. V. (1995). Self ratings of health: Do they also predict change in functional ability? Journals of Gerontology, Series B: Psychological Sciences and Social Sciences, 50, P344-P353.

Kenny, D. A., Kashy, D. A., \& Bolger, N. (1998). Data analysis in social psychology. In D. T. Gilbert \& S. T. Fiske (Eds.), The handbook of social psychology (Vol. 1, pp. 233-265). New York: McGraw-Hill.

King, L. A. (2004). Measures and meanings: The use of qualitative data in social and personality psychology. In C. Sansone, C. C. Morf, \& A. T. Panter (Eds.), Handbook of methods in social psychology (pp. 173-194). Thousand Oaks, CA: Sage.

Labouvie-Vief, G., Hakim-Larson, J., \& Hobart, C. J. (1987). Age, ego level, and the life-span development of coping and defense processes. Psychology and Aging, 2, 286-294.

Lansford, J. E., Antonucci, T. C., Akiyama, H., \& Takahashi, K. (2005). A quantitative and qualitative approach to social relationships and wellbeing in the United States and Japan. Journal of Comparative Family Studies, 36, 1-23.

Lazarus, R. S. (1996). The role of coping in the emotions and how coping changes over the life course. In C. Malastesta-Magai \& S. McFadden (Eds.), Handbook of emotion, adult development, and aging (pp. 289306). Orlando, FL: Academic Press.

Littell, R. C., Milliken, G. A., Stroup, W. W., \& Wolfinger, R. D. (1996) SAS system for mixed models. Cary, NC: SAS Institute.

MacKinnon, D. P., Krull, J. L., \& Lockwood, C. M. (2000). Equivalence of the mediation, confounding, and suppression effect. Prevention Science, 1, 173-181.

Markman, H. J., Silvern, L., Clements, M., \& Kraft-Hanak, S. (1993). Men and women dealing with conflict in heterosexual relationships. Journal of Social Issues, 49, 107-125.

Moen, P. (2001). The gendered life course. In R. H. Binstock (Ed.), Handbook of aging and the social sciences (pp. 179-196). San Diego, CA: Academic Press.

Nolen-Hoeksema, S., Larson, J., \& Grayson, C. (1999). Explaining the gender difference in depressive symptoms. Journal of Personality and Social Psychology, 77, 1061-1072.

Noller, P., \& Feeney, J. A. (1998). Communication in early marriage: 
Responses to conflict, nonverbal accuracy, and conversational patterns. In T. N. Bradbury (Ed.), The developmental course of marital dysfunction (pp. 11-43). Cambridge, England: Cambridge University Press.

Okun, M. A., \& Keith, V. M. (1998). Effects of positive and negative social exchanges with various sources on depressive symptoms in younger and older adults. Journals of Gerontology, Series B: Psychological Sciences and Social Sciences, 53, P4-P20.

Pearlin, L. I., \& Turner, H. A. (1987). The family as a context of the stress process. In S. V. Kasl \& C. L. Cooper (Eds.), Stress and health: Issues in research methodology (pp. 143-165). New York: Wiley.

Putnam, L. L., \& Wilson, C. E. (1982). Communicative strategies in organizational conflicts: Reliability and validity of a measurement scale. In M. Burgoon (Ed.), Communication yearbook (pp. 629-652). Newbury Park, CA: Sage.

Repetti, R. L. (1993). Short-term effects of occupational stressors on daily mood and health complaints. Health Psychology, 12, 125-131.

Rook, K. S. (1984). The negative side of social interaction: Impact on psychological well-being. Journal of Personality and Social Psychology, 5, 1097-1108.

Rusbult, C. E., Bissonnette, V. L., Arriaga, X. B., \& Cox, C. L. (1998). Accommodation processes during the early years of marriage. In T. N. Bradbury (Ed.), The development course of marital dysfunction (pp. 74-113). Cambridge, England: Cambridge University Press.

Rusbult, C. E., Johnson, D. J., \& Morrow, G. D. (1986). Impact of couple patterns of problem solving on distress and nondistress in dating relationships. Journal of Personality and Social Psychology, 50, 744-753.

Schuster, T. L., Kessler, R. C., \& Aseltine, R. H., Jr. (1990). Supportive interactions, negative interactions, and depressed mood. American Journal of Community Psychology, 18, 423-437.
Sillars, A. L. (1986). Procedures for coding interpersonal conflict: The verbal tactics coding scheme (VTCS). Missoula: University of Montana, Department of Communication Studies.

Sillars, A. L., \& Zietlow, P. H. (1993). Investigations of marital communication and lifespan development. In N. Coupland \& J. F. Nussbaum (Eds.), Discourse and lifespan identity (pp. 237-261). Newbury Park, CA: Sage.

Singer, J. D. (1998). Using SAS PROC MIXED to fit multilevel models, hierarchical models, and individual growth models. Journal of Educational and Behavioral Statistics, 23, 323-355.

Straus, M. A. (1979). Measuring intrafamily conflict and violence: The Conflict Tactics (CT) Scales. Journal of Marriage and the Family, 41, $75-88$.

Straus, M. A., \& Gelles, R. J. (1990). Physical violence in American families. New Brunswick, NJ: Transaction.

Strauss, A. L. (1987). Qualitative analysis for social scientists. New York: Cambridge University Press.

Troll, L. E. (1987). Gender differences in cross-generation networks. Sex Roles, 17, 751-766.

Walen, H. R., \& Lachman, M. E. (2000). Social support and strain from partner, family, and friends: Costs and benefits for men and women in adulthood. Journal of Social and Personal Relationships, 17, 5-30.

Watson, T. L., \& Blanchard-Fields, F. (1998). Thinking with your head and your heart: Age differences in everyday problem-solving strategy preferences. Neuropsychology and Cognition, 5, 225-240.

Received December 4, 2003

Revision received January 18, 2005

Accepted February 2, 2005

\section{Instructions to Authors}

For Instructions to Authors, please consult the first issue of the volume or visit www.apa.org/ journals/pag and click on Submission Guidelines. 